\title{
Increased expression of CYP17A1 indicates an effective targeting of the androgen receptor axis in castration resistant prostate cancer (CRPC)
}

\author{
Felix Bremmer ${ }^{1}$, Hubertus Jarry ${ }^{2}$, Arne Strauß ${ }^{3}$, Carl Ludwig Behnes ${ }^{1}$, Lutz Trojan ${ }^{3}$ and Paul Thelen ${ }^{3 *}$
}

\begin{abstract}
Recent breakthrough therapies targeting androgen receptor signalling in castration resistant prostate cancer (CRPC) involve multifunctional androgen receptor (AR) blockade and exhaustive androgen deprivation. Nevertheless, limitations to an enduring effectiveness of new drugs are anticipated in resistance mechanisms occurring under such treatments.

In this study we used CRPC cell models VCaP and LNCaP as well as AR-negative PC-3- and non-neoplastic epithelial $\mathrm{BPH}-1$-cells treated with 5, 10 or $25 \mu \mathrm{mol} / \mathrm{L}$ abiraterone hydrolyzed from abiraterone acetate (AA). The origin of CYP17A1 up-regulation under AA treatment was investigated in CRPC cell models by qRT-PCR and western-blot procedures.

AA treatments of AR positive CRPC cell models led to decreased expression of androgen regulated genes such as PSA. In these cells diminished expression of androgen regulated genes was accompanied by an up-regulation of CYP17A1 expression within short-term treatments. No such effects became evident in AR-negative PC-3 cells. AR directed siRNA (siAR) used in VCaP cells significantly reduced mRNA expression and AR protein abundance. Such interference with AR signalling in the absence of abiraterone acetate also caused a marked up-regulation of CYP17A1 expression. Down-regulation of androgen regulated genes occurs in spite of an elevated expression of CYP17A1, the very target enzyme for this drug. CYP17A1 up-regulation already takes place within such short treatments with AA and does not require adaptation events over several cell cycles. CYP17A1 is also up-regulated in the absence of AA when AR signalling is physically eliminated by siAR.

These results reveal an immediate counter-regulation of CYP17A1 expression whenever AR-signalling is inhibited adequately but not a persisting adaptation yielding drug resistance.
\end{abstract}

Keywords: Abiraterone acetate; CYP17A1; CRPC; Androgen receptor; IGF-2

\section{Background}

Prostate cancer is the second leading cause of cancer death from the most frequently diagnosed malignancy in males in the USA. As well in Europe prostate cancer accounts for $9 \%$ of total cancer-related deaths. Standard treatments for localized prostate cancer are radical surgery, radiation therapy or active surveillance (Ferlay et al. 2007; Jemal et al. 2011). However conventional therapies may fail as almost one-third of patients who undergo local

\footnotetext{
* Correspondence: pthelen@gwdg.de

${ }^{3}$ Department of Urology, University Medical Center, University of Göttingen, Robert-Koch-Str. 40, 37075 Göttingen, Germany

Full list of author information is available at the end of the article
}

treatment will experience relapse and will receive androgen deprivation therapy (Kantoff and Mohler 2013).

Within the last three years two alternative antiandrogen strategies reached clinical application offering new options in both pre- and post-chemotherapy setting which emphasises the androgen receptor as sustained therapy target in prostate cancer. Chemotherapy often succeeds temporarily following therapy failure of conventional hormone therapies. New drugs including abiraterone acetate (AA) and enzalutamide, effectively target the androgen pathway to arrest aberrant signalling even after multiple therapies. The mode of action of these new compounds is either inhibition of androgen synthesis at the CYP17A1 enzyme covering also adrenal and 
intracrine androgen sources, or a full androgen receptor (AR) blockade antagonizes the AR function by directly binding this transcription factor with high affinity. Nevertheless, clinical success of these novel drugs is not enduring in all cases. Recent phase 3 trials revealed median time to PSA progression of about eight months for both drugs and in sequential treatments of enzalutamide and AA cross resistances have to be considered (Schrader et al. 2013). Whilst the molecular mechanisms for cross resistances occurring after sequential use of androgen ablation and androgen receptor blockade are still elusive, the alterations leading to individual therapy resistance have been addressed in more detail. The resistance mechanisms can be distinguished between AR amplification/overexpression including alternative AR splice variants (e.g. $\mathrm{VCaP}$ ) and gain-of-function $\mathrm{AR}$ mutations in the ligand binding domain (e.g. LNCaP) associated with anti-androgen treatments notably flutamide or bicalutamide (Knudsen and Penning 2010; Waltering et al. 2012). Even for the second-generation anti-androgen enzalutamide a ligand binding domain mutation has been identified which converts the drug from an AR antagonist to an AR agonist. However, this mutation was identified in a mutagenesis screen in cell models (Balbas et al. 2013).

Recent considerations of actual therapy resistance include newly acquired mechanisms within the AR-axis under the individual treatment and do not necessarily require ultimate castration resistance as in AR-negative cell models of prostate cancer (Feldman and Feldman 2001). In case of CYP17A1 inhibitor treatments an increased expression of CYP17A1 thereafter was assumed as a potential mechanism and dose escalation or combined treatments with enzalutamide were suggested to cope with this effect (Cai et al. 2011; Richards et al. 2012; Mostaghel et al. 2011). In the present study we analyse the causation of CYP17A1 up-regulation and discuss how this phenomenon qualifies for a therapy resistance mechanism in distinct prostate and CRPC cell models varying in AR status.

\section{Methods}

\section{Culture cell lines and treatment}

Human prostate cancer cell line VCaP was purchased from ATCC, Wesel, Germany and kept in Phenol red-free Gibco ${ }^{\circ}$ DMEM lot \# 1089200 (Life Technologies $\mathrm{GmbH}$, Darmstadt, Germany) supplemented with 2\% sodium pyruvate and $10 \%$ foetal calf serum (PAA, Cölbe, Germany). The other cell lines LNCaP, PC-3 and BPH-1 from permanent local stocking were certified to proof origin (Fuessel et al. 2013). Cells were incubated at $37{ }^{\circ} \mathrm{C}$ and $5 \% \mathrm{CO}_{2}$ in a humidified incubator. Cells and supernatants were harvested for RNA and protein extraction or used for ELISA assays. PSA release into cell culture media was measured with PSA-ELISA EIA-3719, (DRG Instruments, Marburg, Germany). This study did not require an approval from an ethics committee and the local animal protection committee.

Abiraterone acetate (Janssen Cilag, Neuss, Germany) was used for treatments in 5,10 or $25 \mu \mathrm{mol} / \mathrm{L}$ concentration performed for 24 hours. To obtain the active drug hydroxy-abiraterone (AA), abiraterone acetate was hydrolysed in 95\% ethanol prior to use (Soifer et al. 2012).

\section{siRNA transfection}

The VCaP cells were transfected with siRNAs against the androgen receptor (Riboxx Radebeul, Germany). To select for best AR interference four different sequences were used (Table 1). We chose the siRNA sequence ARex7 which had the highest down-regulation to $16 \%$ of regular expression (Additional file 1: Figure S1). Before transfection for $24 \mathrm{~h}, 10^{5}$ tumour cells were plated in six well plates for $48 \mathrm{~h}$ in DMEM. The transfection medium consists of $10 \mu \mathrm{l}$ from a $20 \mu \mathrm{mol} / \mathrm{l}$ oligonucleotide stock solution, $5 \mu \mathrm{l}$ Oligofectamine reagent, $185 \mu \mathrm{l}$ Opti-MEM according to the manufacturer recommendation (Life Technologies $\mathrm{GmbH}$ ). Luciferase (LUC) siRNA was used for control transfections (Eurogentec, Cologne, Germany).

\section{mRNA-expression analysis}

mRNA-expression of PSA, TMPRSS2-ERG, CYP17A1, AKR1C3, AR and IGF-2 were analysed by qRT-PCR. Total cellular RNA from cultured cells was extracted

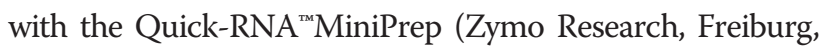
Germany). Total RNA integrity and quantity were assessed on an Agilent Bioanalyzer 2100 with a RNA 6000 Nano LabChipKit (Agilent Technologies, Waldbronn, Germany). Reverse transcription of $500 \mathrm{ng}$ total cellular (tc) RNA was performed with random hexamer primers and an Omniscript RT Kit (QIAGEN, Hilden, Germany). Expression analyses were processed on an iCycler iQ real time detection system (BIORAD, Munich, Germany) with SsoFast EvaGreen supermix. The $20 \mu \mathrm{l}$ reaction from the kit was supplemented with $2 \mu \mathrm{l}$ cDNA, $0.6 \mu \mathrm{M}$ gene-specific primers (IBA, Göttingen, Germany). Primers were designed by Primer 3 and PCR efficiency was assessed as previously described (Stettner et al. 2007).

Table 1 Different sequences of siRNA against the AR

\begin{tabular}{lll}
\hline & Sequence & Sense strand \\
\hline ARex2 & 5'-UUGAAGAAGACCUUGCA & 5'-GGGGGCUGCAAGGUCUU \\
& GCCCCC-3' & CUUCAA-3' \\
ARex2/3 & 5'-ACUUCUGUUUCCCUUCA & 5'-GGGGGCUGAAGGGAAAC \\
& GCCCCC-3' & AGAAGU-3' \\
ARex4 & 5'-AUUACCAAGUUUCUUCA & 5'-GGGGGCUGAAGAAACUU \\
& GCCCCC-3' & GGUAAU-3' \\
ARex7 & 5'-AUCUCUGCCAUCAUUUC & 5'-GGGGGCGGAAAUGAUGG \\
& CGCCCCC-3' & CAGAGAU-3' \\
\hline
\end{tabular}




\section{Western blot analysis}

Protein expression was measured by western blot analysis with androgen receptor antibody Ab-2 (Cat. \# RB-1358, Lab Visions Corp. Fremond, CA, USA) and CYP17A1 antibody (Cat. 14447-1-AP, protein tech, Manchester, United Kingdom) where $\alpha$-tubulin was used as loading control detected with a monoclonal anti- $\alpha$-tubulin (clone B-5-1-2, \# T 5168, Sigma, St. Louis, MO, USA). Cells were homogenized with Pierce ${ }^{\circ}$ RIPA buffer (Thermo Scientific, Rockford, IL, USA). Novex ${ }^{\circ}$ precast gels (Life Technologies, Darmstadt, Germany) were used for electrophoresis followed by electro-transfer onto Protran $^{\circ}$ nitrocellulose membranes (Whatman $\mathrm{GmbH}$, Dassel, Germany) from where protein-bound membrane was hybridized with antibodies. For visualization, we used Western Lightning ${ }^{\circ}$ Plus-ECL (Perkin Elmer, Waltham, MA, USA), rabbit secondary antibodies (P 0448 Dako, Glostrup, Denmark) and ProteinSimple FluorChem E (BioZym Hess. Oldendorf, Germany). For quantification of band intensity Image J (http://imagej.nih.gov/ij/) was used.

\section{Statistical analyses}

Statistical calculation, mean $+/-\mathrm{SD}$ and $\mathrm{P}$ values were carried out with GraphPad Prism software version 5.0 using the unpaired nonparametric $t$ test at $95 \%$ confidence interval considered statistically significant $\left(*=\mathrm{p}<0.05,{ }^{* * *}=\right.$ $\mathrm{p}<0.005$ and ${ }^{* * * *}=\mathrm{p}<0.0005$ ).

\section{Results}

\section{Treatment of VCaP and LNCaP Cells with AA}

CRPC cell line VCaP with overexpressed AR and LNCaP with a gain-of-function AR mutation were treated with 5,10 or $25 \mu \mathrm{mol} / \mathrm{L}$ AA. In both cell lines PSA mRNA expression decreased after treatment with AA (Figure $1 \mathrm{~A}+\mathrm{B}$ ). The same effect was found for TMPRSS2-ERG expression in the VCaP cell line (Figure 1C). According to the PSA mRNA expression the PSA secretion also decreased (Figure 1D). In the same experiments we looked for the expression profile of CYP17A1 and AKR1C3. Concomitantly with the detected decrease of androgen regulated genes PSA and TMPRSS2-ERG, in both cell lines the CYP17A1 expression level significantly increased after treatment with $25 \mu \mathrm{mol} / \mathrm{L} \mathrm{AA}$ (Figure $2 \mathrm{~A}+\mathrm{B}$ ). In contrast, the downstream enzyme in testosterone biosynthesis, AKR1C3, reveals decreased mRNA expression levels under such treatments in VCaP but not in LNCaP cells (Figure $2 \mathrm{C}+\mathrm{D}$ ). Counter-regulated CYP17A1 and AKR1C3 mRNA levels were also found in the non-neoplastic cell line BPH-1 (Figure $3 \mathrm{~A}+\mathrm{B}$ ) indicating an association of this phenomenon with a non-mutated ligand binding domain of the AR. In contrast to all other cell models the ARnegative, malignant tumour cell line $\mathrm{PC}-3$ treated with AA does not show any significant effects on CYP17A1 and AKR1C3 expression (Figure 3C + D).

\section{Targeting the AR in VCaP cells with siRNA elicits CYP17A1-up-regulation in absence of AA}

A siRNA against AR transcripts was used to elucidate the relevance of AR signalling to the effects on CYP17A1 and AKR1C3 expression in the absence of the compound AA. AR directed siRNA significantly reduced AR mRNA-expression and is also seen in western blot analysis (Figure 4A), albeit high AR expression is persistent in $\mathrm{VCaP}$ cells. However, this interference with $\mathrm{AR}$ expression in the absence of AA also caused an up-regulation of CYP17A1 expression in $\mathrm{VCaP}$ cells (Figure 4B), but had only marginal effects on AKR1C3 expression (Figure 4C). Therefore, CYP17A1 up-regulation is not dependent on AA presence and is based upon AR impairment.

\section{CYP17A1 enzyme inhibition and androgen receptor expression under $A A$ treatment}

To elucidate by which function in AR signaling, receptor status or androgen synthesis, androgen regulated genes are affected, western blot analysis for the AR and CYP17A1 were performed. In these experiments VCaP cells were treated with $5 \mu \mathrm{mol} / \mathrm{L}$ AA. No significant changes were detected on the AR protein level calculated from western blot analyses (Figure $5 \mathrm{~A}+\mathrm{C}$ ), whereas in the same experiment CYP17A1 protein expression increased markedly (Figure $5 B+C$ ). This experiment excludes a loss of $\mathrm{AR}$ expression as an explanation for diminished androgen receptor signaling and implies a full arrest of CYP17A1-mediated androgen synthesis by AA even when the enzyme was overexpressed.

\section{Correlation of AA treatment effects on steroidogenesis and IGF-2 expression}

As the entire IGF-axis has significant influence on mechanisms of castration resistance, IGF-2 is involved in pathways which can induce de novo steroidogenesis. Therefore, we investigated the influence of AA on IGF-2 expression in our different prostate cell models. Concomitant with decreased expression of androgen regulated genes despite CYP17A1 up-regulation, IGF-2 expression was also upregulated with increasing $\mathrm{AA}$ concentrations in $\mathrm{VCaP}$ CRPC cells (Figure 6A). We also established a VCaP variant reverted to androgen sensitivity termed $\mathrm{VCaP}$ CRPCrev. These cells growing steadily under $1 \mathrm{nmol} / \mathrm{L}$ testosterone showed a similar basic level of IGF-2 expression which was not elevated with treatments of increasing AA concentrations (Figure 6B). This indicates a marker function of IGF-2 for androgen deprivation. Under these conditions LNCaP only showed an increased IGF-2 expression after treatments of $25 \mu \mathrm{mol} / \mathrm{L}$ AA (Figure $6 \mathrm{C}$ ). In contrast the 

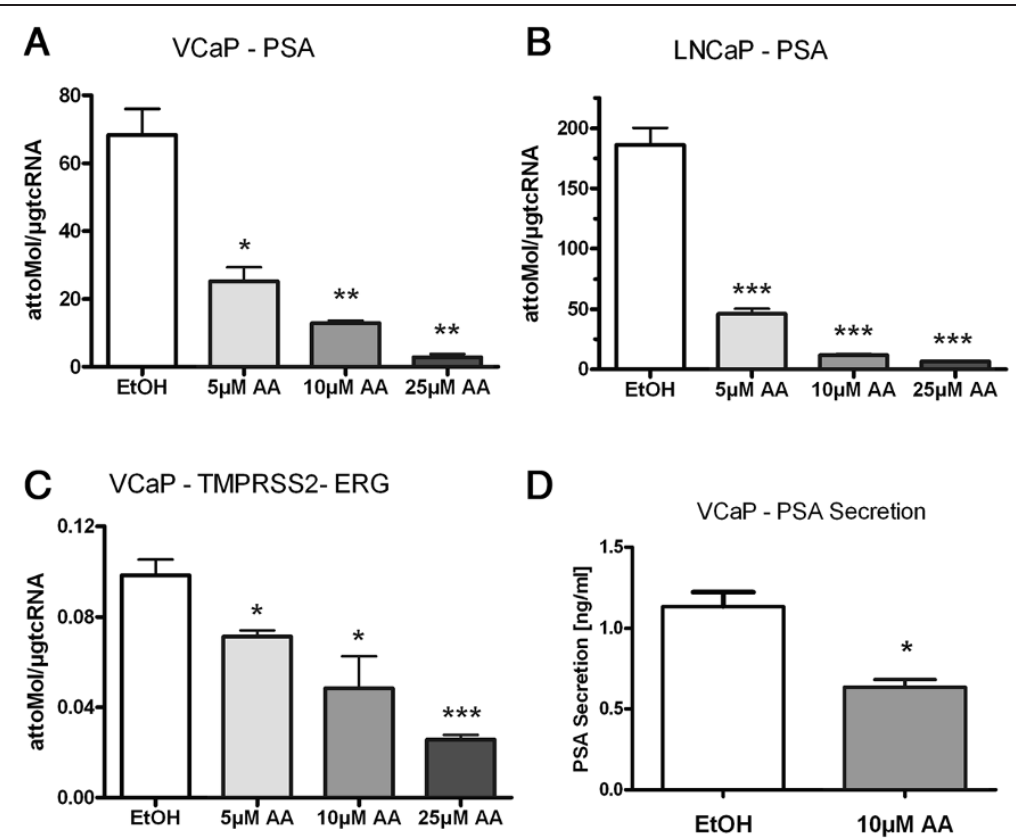

Figure 1 Expression profile of PSA and TMPRSS2-ERG: VCaP and LNCaP showing decreased PSA and TMPRSS2-ERG (VCaP) mRNA expression after treatment with with 5,10 or $25 \mu \mathrm{M}$ AA (A-C). In addition treatment with $10 \mu \mathrm{M}$ AA leads to a decreased PSA secretion in $\operatorname{VCaP}(\mathbf{D}) ;\left(^{*}=p<0.05,^{* *}=p<0.005\right.$ and $\left.{ }^{* *}=p<0.0005\right)$.

non-neoplastic BPH-1 cells revealed a stepwise increase of IGF-2 expression (Figure 6D) similar to VCAP CRPC cells (Figure 6A). Interestingly, also AR negative malignant prostate cancer cells (PC-3) exhibit an increased IGF-2 expression like $\mathrm{LNCaP}$ at higher AA concentration (Figure 6E). In these PC-3 cells this increase of IGF-2 expression in contrast to AR expressing cells is not associated with an increase of CYP17A1 expression (Figure 3C).

\section{Discussion}

The huge progress made in the past few years to treat CRPC with hormonal manipulation or AR blockade caused
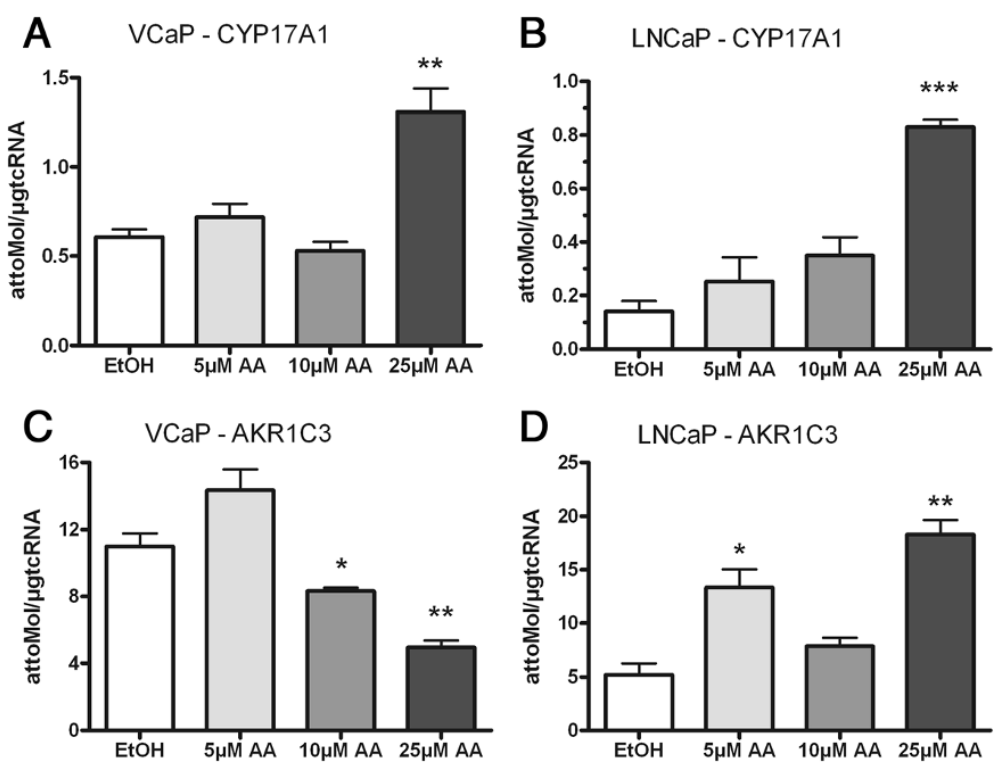

Figure 2 Expression profile of CYP17A1 and AKR1C3: CYP17A1 expression level is significantly increased in VCaP and LNCaP after treatment with $25 \mu \mathrm{m}$ AA $(\mathbf{A}+\mathbf{B})$. In addition AKR1C3 mRNA is decreased in VCaP and increased in LNCaP cell line $(\mathbf{C}+\mathbf{D}) ;\left(^{*}=p<0.05\right.$, ${ }^{* *}=p<0.005$ and $\left.^{* * *}=p<0.0005\right)$. 

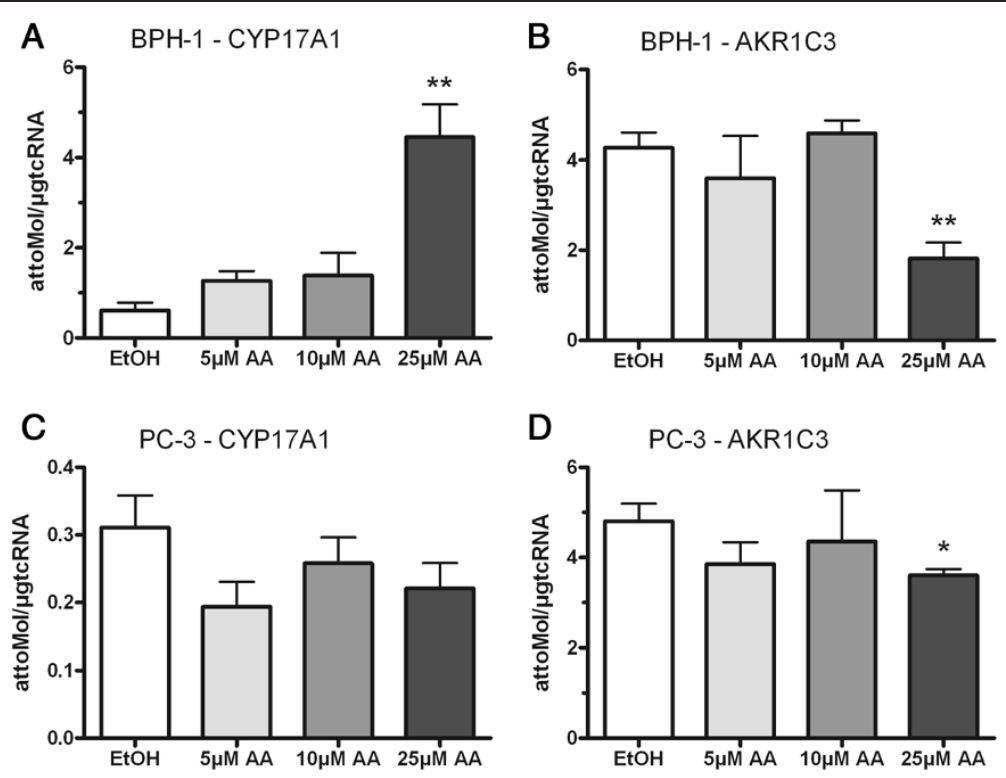

Figure 3 CYP17A1 and AKR1C3 expression in BPH-1 and PC3: increased CYP17A1 and decreased AKR1C3 mRNA in BPH-1 after treatment with $25 \mu \mathrm{M}$ AA (A + B). In PC-3 no significant effects after AA treatment in CYP17A1 and AKR1C3 mRNA expression could be seen $(\mathbf{C}+\mathbf{D}) ;\left(^{*}=p<0.05,{ }^{* *}=p<0.005\right.$ and $\left.{ }^{* * *}=p<0.0005\right)$.

confidence in prostate cancer therapy but may be compromised by resistance mechanisms acquired under these novel treatments (Yuan et al. 2013). Therapy resistance may result of ultimate castration resistance or other undefined escape mechanisms. Such therapy resistances developing under treatment and hence selective pressure on tumour cells are distinguishable from mechanisms responsible for initial therapy failure in non-responding patients. One obvious explanation for therapy induced resistance is tumour growth of androgen independent cell clones as evident in tumour cell models (Balbas et al. 2013; Sharma et al. 2010). Furthermore, therapy resistance developed under AA treatments has been explained by treatment-induced selection of tumour cells with elevated
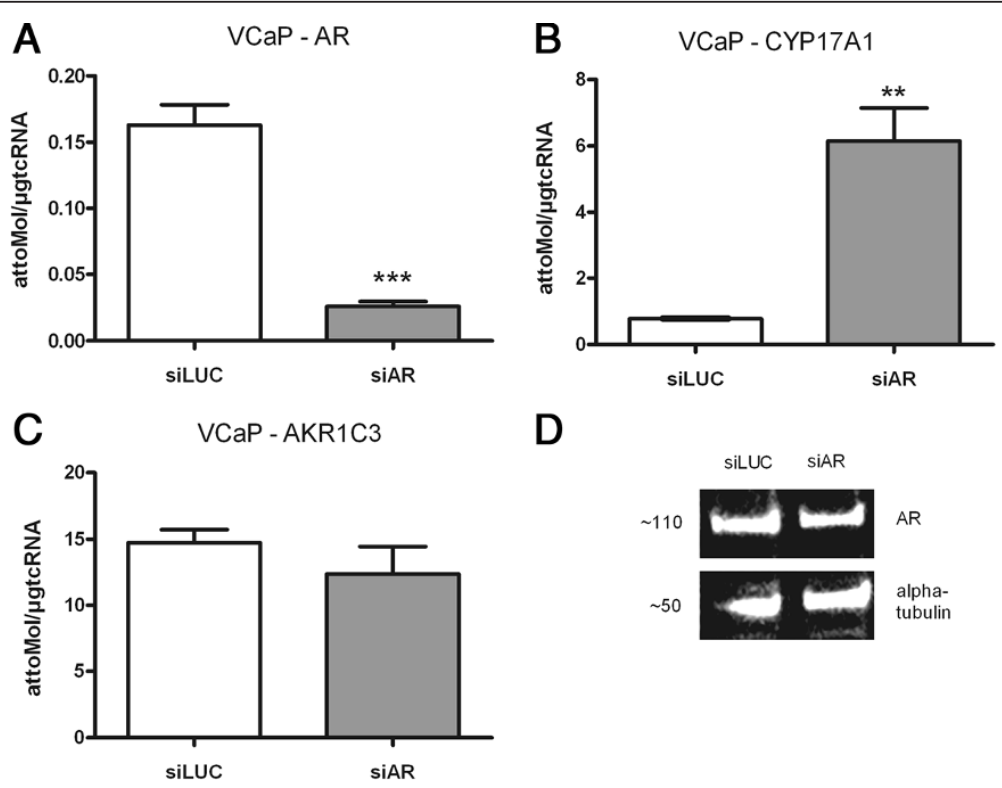

D

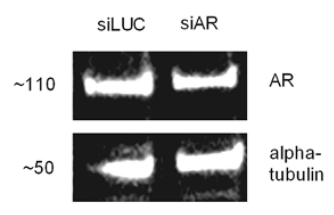

Figure 4 AR targeting siRNA in VCaP: siRNA against AR significantly reduced AR expression and an up-regulation of CYP17A1 expression in the absence of AA. No such effect is seen in AKR1C3 mRNA expression levels (A-D); $\left({ }^{*}=p<0.05,{ }^{* *}=p<0.005\right.$ and $\left.{ }^{* * *}=p<0.0005\right)$. 

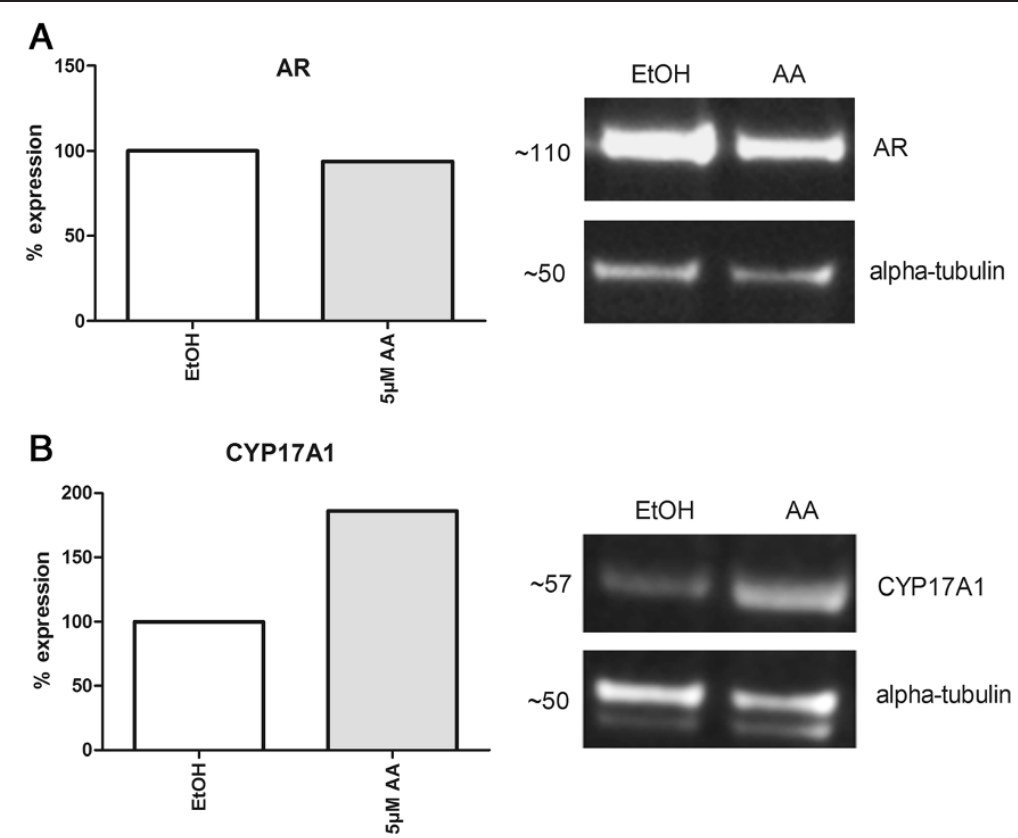

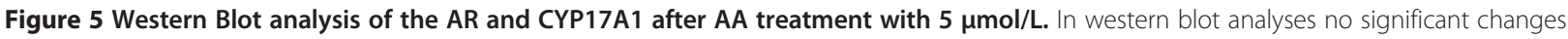
were detected on the AR protein level (A), whereas CYP17A1 protein expression increased markedly (B).

intratumoural expression of CYP17A1. Indeed in a study by Cai et al. an increased mRNA becomes evident in VCaP xenograft tumour bearing mice after long-term AA treatments, whereas only one in four xenografts had increased CYP17A1 expression in short term treatments with the drug (Cai et al. 2011). From this phenomenon the authors infer a de novo intratumoural steroid synthesis and a mechanism contributing to AR reactivation and resistance to CYP17A1 inhibitors.

In our short term in vitro experiments in $\mathrm{VCaP}$ cells, however, we found an increased CYP17A1 expression with increasing concentrations of AA within 24 hours. Despite countering CYP17A1 expression androgen regulated genes such as PSA or the fusion transcript TMPRSS2-ERG were down-regulated with increasing AA concentrations, indicating sufficiently suppressed androgen receptor signalling in the presence of the drug. This confirms a still complete inhibition by AA of basal and surplus CYP17A1 enzyme activity under continuous treatment. To exclude an alternative explanation for this finding we calculated AR expression and CYP17A1 expression side-by-side from western blot analyses (Figure 5). Hence, AR expression is not affected by AA treatments with low concentrations of $5 \mu \mathrm{mol} / \mathrm{L}$ whereupon CYP17A1 is elevated then. This lead to the conclusion that an inhibition of androgen signalling in the presence of overexpressed CYP17A1 was not due to altered AR expression.

Based on AR alterations there are two distinct explanations for castration resistance and evolving therapy resistance. One is AR overexpression to retrieve trace amounts of androgens and the other selection for ligand binding domain mutations to utilize a variety of alternative ligands for activation (Balbas et al. 2013).

Although a direct interaction of AA with the AR and a switch to an agonist of a mutated AR has been discussed as mechanism for therapy resistance (Cronauer et al. 2013), our results can all be explained by an exclusive AA effect on steroidogenesis and low affinity to AR. Actually, selection for a gain-of-function mutation in prostate cancer cells is most conceivable when androgens are scarce as under androgen deprivation and in the presence of high-affinity AR ligand. A therapy resistance based upon this principle may only arise under androgen deprivation in combination with an anti-androgen with demonstrable high affinity to the androgen receptor. With an effective binding of a ligand, the incidence of a gain-of-function mutation which turns an anti-androgen into an androgen thusly granted prevalence for an activated mutated AR no longer blocked by the antiandrogen. Therefore, therapy resistance, especially a most menacing anti-androgen withdrawal phenomenon is more comprehensible for anti-androgen therapy than androgen deprivation. In this study we showed that CYP17A1 up-regulation, the presumed resistance mechanism to AA therapy is not restricted to androgen signalling in the de facto presence of AA. When androgen signalling is impaired by other means e.g. by RNA interference with AR expression by specific siRNA (Figure 4) the same 

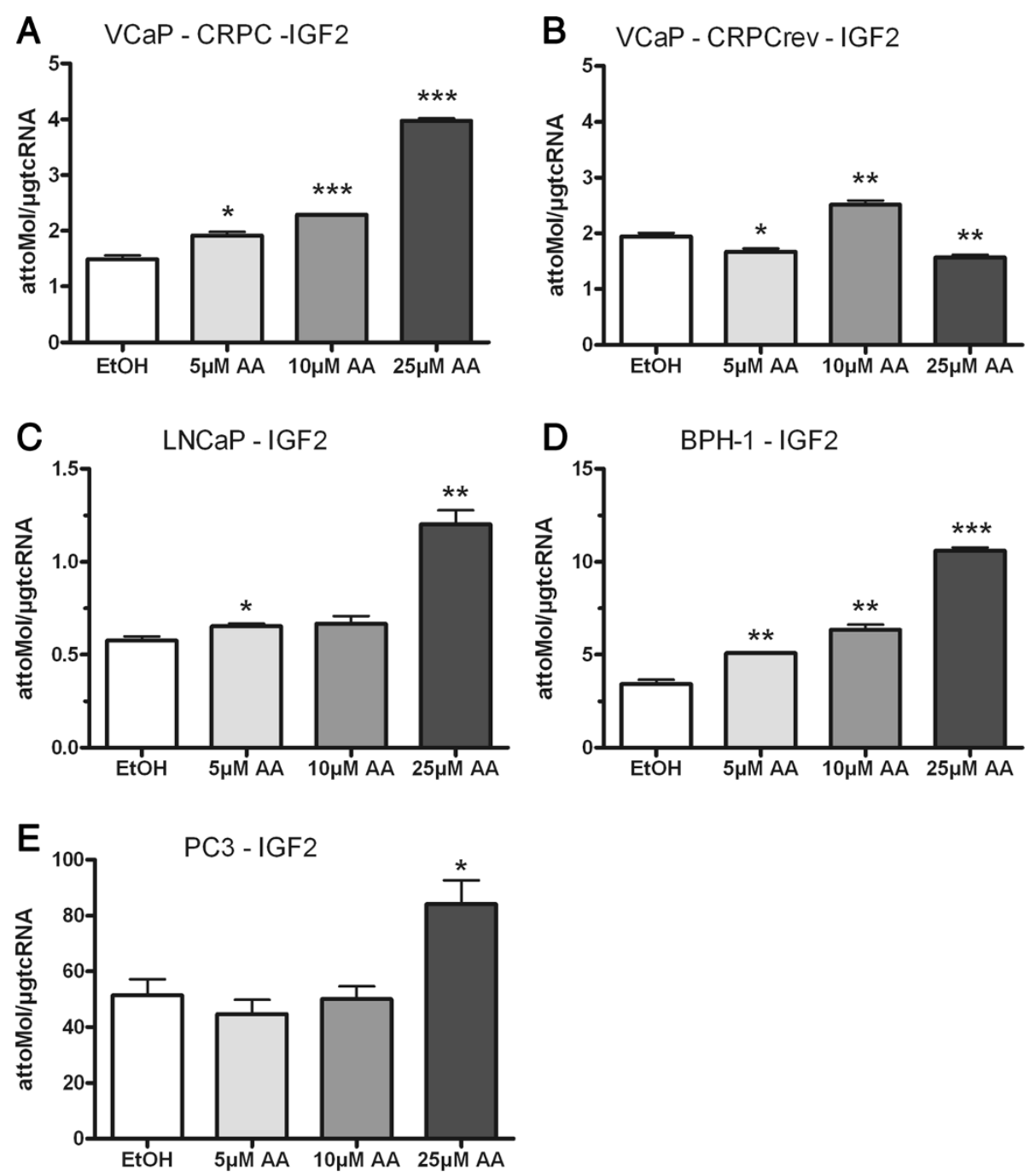

Figure 6 Correlation of AA treatment on IGF-2 expression: IGF-2 is up-regulated in VCaP-CRPC, LNCaP, BPH-1 and PC3 after treatment with $25 \mu \mathrm{m}$ AA (A, C-E). In contrast IGF-2 expression was not elevated after treatments of increasing AA concentrations in VCaP-CRPCrev (B); $\left({ }^{*}=p<0.05,{ }^{* *}=p<0.005\right.$ and $\left.{ }^{* * *}=p<0.0005\right)$.

effect becomes evident. Interestingly, $\mathrm{VCaP}$ cells under hydroxyl-flutamide or bicalutamide treatment also showed up-regulated CYP17A1 and down-regulated AKR1C3 expression (Kumagai et al. 2013), we demonstrated for AA treatments (Figure 1). Therefore, CYP17A1 up-regulation obviously is indicative for effective impairment of AR signalling in general not limited to AA treatments and may represent a negative feedback loop (Auchus and Auchus 2012). Although all AA effects on AR positive cells VCaP, LNCaP and BPH-1 appear to be attributed to an inhibitory influence on steroidogenesis, our results from AR knockdown experiments and AR negative PC-3 cells cannot fully exclude the notion of AA binding the AR and partly inhibiting AR-signalling. There are conflicting results from previous studies which either excluded binding of AA to $\mathrm{AR}$ or detected direct AA binding to the AR in vitro assays despite low affinity as compared with pure antiandrogens (Handratta et al. 2005; Richards et al. 2012).

Our study revealed that a therapy resistance to AA treatments is not satisfactorily explained by sole CYP17A1 upregulation. In addition to an up-regulation of CYP17A1 expression under AA treatments we also showed an increased expression of IGF-2 in a concentration dependent manner. Recent studies revealed new molecular pathways by which IGF-2 confers androgen independent growth or can ignite the de novo steroidogenesis engine and promote molecular events associated with tumour progression evading hormone therapy (Lubik et al. 2013; Comstock and Knudsen 2013). IGF2 can activate the IGF1 receptor or insulin receptor or hybrids of these two receptors to contribute to prostate cancer progression to castration resistance (Lubik et al. 2011). Further studies are warranted 
to evaluate a switch from steroid hormones to mitogenic peptide hormones such as IGF-2 as response to androgen deprivation and antiandrogen therapy and possible escape mechanism to be targeted selectively in new therapy attempts.

\section{Conclusions}

An up-regulation of CYP17A1 expression under AA treatments is inconsistent with otherwise identified benefits in CRPC therapy. The CYP17A1 up-regulation under AA is not restricted to tumour cells but is elicited when AR signaling is impaired. Therefore, this phenomenon represents an immediate feedback loop upon AR impairment, rather than an acquired, persisting drug resistance mechanism. This means the search for the mechanisms of therapy resistance in CRPC is not over. However, the recent anticipation of cross resistances after various anti-androgen concepts suggests the last resort of therapy resistant tumour cells is narrowed down to only few options. Therefore, further research is warranted to target these escape mechanisms unerringly, when even up-to-date regimens begin to falter.

\section{Ethical standards}

This study did not require an approval from an ethics committee and the local animal protection committee.

\section{Additional file}

Additional file 1: Figure S1. Effect of siRNA against the AR: ARex7 downregulation to $16 \%$, ARex2 to $26 \%$, ARex $2 / 3$ to $40 \%$ and ARex 4 to $56 \%$.

\begin{abstract}
Abbreviations
CRPC: Castration resistant prostate cancer; AR: Androgen receptor; AA: Abiraterone acetate; CYP17A1: Cytochrome P450 17A1; IGF-2: Insulin-like growth factor; AKR1C3: Aldoketone reductase; TMPRSS2-ERG: Transmembrane protease, serine 2 ets related gene.
\end{abstract}

\section{Competing interests}

The authors declare that they have no competing interests.

\section{Authors' contributions}

FB and PT were responsible for the execution of all experiments, drafted the manuscript and designed figures and tables. $\mathrm{HJ}$ and CLB assisted in manuscript preparation and experimental procedures. AS and LT provided clinical information concerning prostate cancer treatments. All authors read and approved the final manuscript.

\section{Acknowledgements}

We thank Marion Striepe for excellent technical assistance in all experiments. Felix Bremmer, Paul Thelen and Hubertus Jarry are supported by Deutsche Forschungsgemeinschaft (DFG).

\section{Author details}

${ }^{1}$ Institute of Pathology, University Medical Center, University of Göttingen, Robert-Koch-Str. 40, 37075 Göttingen, Germany. ${ }^{2}$ University Medical Center, University of Göttingen, Göttingen, Germany. ${ }^{3}$ Department of Urology, University Medical Center, University of Göttingen, Robert-Koch-Str. 40, 37075 Göttingen, Germany.
Received: 27 June 2014 Accepted: 26 September 2014

Published: 1 October 2014

\section{References}

Auchus ML, Auchus RJ (2012) Human steroid biosynthesis for the oncologist. J Investig Med 60(2):495-503. doi:10.231/JIM.0b013e3182408567

Balbas MD, Evans MJ, Hosfield DJ, Wongvipat J, Arora VK, Watson PA, Chen Y, Greene GL, Shen Y, Sawyers CL (2013) Overcoming mutation-based resistance to antiandrogens with rational drug design. eLife 2:e00499. doi:10.7554/eLife.00499

Cai C, Chen S, Ng P, Bubley GJ, Nelson PS, Mostaghel EA, Marck B, Matsumoto AM, Simon NI, Wang H, Balk SP (2011) Intratumoral de novo steroid synthesis activates androgen receptor in castration-resistant prostate cancer and is upregulated by treatment with CYP17A1 inhibitors. Cancer Res 71(20):6503-6513. doi:10.1158/0008-5472.CAN-11-0532

Comstock CE, Knudsen KE (2013) IGF2 revs the steroidogenesis engine. Endocr Relat Cancer 20(5):C19-C21. doi:10.1530/ERC-13-0243

Cronauer MV, Schrader MG, Schrader AJ (2013) Re: J.A. Witjes: a case of abiraterone acetate withdrawal. Eur Urol 64:517-518. doi:10.1016/j.eururo.2013.08.035

Feldman BJ, Feldman D (2001) The development of androgen-independent prostate cancer. Nat Rev Cancer 1(1):34-45. doi:10.1038/35094009

Ferlay J, Autier P, Boniol M, Heanue M, Colombet M, Boyle P (2007) Estimates of the cancer incidence and mortality in Europe in 2006. Ann Oncol 18(3):581-592. doi:10.1093/annonc/mdl498

Fuessel S, Grobholz R, Krause H, Nawroth R, Thelen P, Schulz W, Unteregger G (2013) Prostate cancer cell lines: identity stability and (cross) contamination. Urologe A 52(Suppl 1):132

Handratta VD, Vasaitis TS, Njar VC, Gediya LK, Kataria R, Chopra P, Newman D, Jr, Farquhar R, Guo Z, Qiu Y, Brodie AM (2005) Novel C-17-heteroaryl steroidal CYP17 inhibitors/antiandrogens: synthesis, in vitro biological activity, pharmacokinetics, and antitumor activity in the LAPC4 human prostate cancer xenograft model. J Med Chem 48(8):2972-2984. doi:10.1021/ jm040202w

Jemal A, Bray F, Center MM, Ferlay J, Ward E, Forman D (2011) Global cancer statistics. CA Cancer J Clin 61(2):69-90. doi:10.3322/caac.20107

Kantoff PW, Mohler JL (2013) New developments in the management of prostate cancer. J Natl Compr Canc Netw 11(5 Suppl):653-657

Knudsen KE, Penning TM (2010) Partners in crime: deregulation of AR activity and androgen synthesis in prostate cancer. Trends Endocrinol Metab 21(5):315-324. doi:10.1016/j.tem.2010.01.002

Kumagai J, Hofland J, Erkens-Schulze S, Dits NF, Steenbergen J, Jenster G, Homma Y, De Jong FH, Van Weerden WM (2013) Intratumoral conversion of adrenal androgen precursors drives androgen receptor-activated cell growth in prostate cancer more potently than de novo steroidogenesis. Prostate 73(15):1636-1650. doi:10.1002/pros.22655

Lubik AA, Gunter JH, Hendy SC, Locke JA, Adomat HH, Thompson V, Herington A, Gleave ME, Pollak M, Nelson CC (2011) Insulin increases de novo steroidogenesis in prostate cancer cells. Cancer Res 71(17):5754-5764. doi:10.1158/0008-5472. CAN-10-2470

Lubik AA, Gunter JH, Hollier BG, Ettinger S, Fazli L, Stylianou N, Hendy SC, Adomat HH, Gleave ME, Pollak M, Herington A, Nelson CC (2013) IGF2 increases de novo steroidogenesis in prostate cancer cells. Endocr Relat Cancer 20(2):173-186. doi:10.1530/ERC-12-0250

Mostaghel EA, Marck BT, Plymate SR, Vessella RL, Balk S, Matsumoto AM, Nelson PS, Montgomery RB (2011) Resistance to CYP17A1 inhibition with abiraterone in castration-resistant prostate cancer: induction of steroidogenesis and androgen receptor splice variants. Clin Cancer Res 17(18):5913-5925. doi:10.1158/1078-0432.CCR-11-0728

Richards J, Lim AC, Hay CW, Taylor AE, Wingate A, Nowakowska K, Pezaro C, Carreira S, Goodall J, Arlt W, McEwan IJ, De Bono JS, Attard G (2012) Interactions of abiraterone, eplerenone, and prednisolone with wild-type and mutant androgen receptor: a rationale for increasing abiraterone exposure or combining with MDV3100. Cancer Res 72(9):2176-2182. doi:10.1158/ 0008-5472.CAN-11-3980

Schrader AJ, Boegemann M, Ohlmann CH, Schnoeller TJ, Krabbe LM, Hajili T, Jentzmik F, Stoeckle M, Schrader M, Herrmann E, Cronauer MV (2013) Enzalutamide in Castration-resistant prostate cancer patients progressing after docetaxel and abiraterone. Eur Urol doi:10.1016/j.eururo.2013.06.042

Sharma A, Yeow WS, Ertel A, Coleman I, Clegg N, Thangavel C, Morrissey C, Zhang X, Comstock CE, Witkiewicz AK, Gomella L, Knudsen ES, Nelson PS, Knudsen KE (2010) The retinoblastoma tumor suppressor controls androgen 
signaling and human prostate cancer progression. J Clin Invest 120(12):4478-4492. doi:10.1172/JC144239

Soifer HS, Souleimanian N, Wu S, Voskresenskiy AM, Collak FK, Cinar B, Stein CA (2012) Direct regulation of androgen receptor activity by potent CYP17 inhibitors in prostate cancer cells. J Biol Chem 287(6):3777-3787. doi:10.1074/jbc.M111.261933

Stettner M, Kaulfuss S, Burfeind P, Schweyer S, Strauss A, Ringert RH, Thelen P (2007) The relevance of estrogen receptor-beta expression to the antiproliferative effects observed with histone deacetylase inhibitors and phytoestrogens in prostate cancer treatment. Mol Cancer Ther 6(10):2626-2633. doi:10.1158/ 1535-7163.MCT-07-0197

Waltering KK, Urbanucci A, Visakorpi T (2012) Androgen receptor (AR) aberrations in castration-resistant prostate cancer. Mol Cell Endocrinol 360(1-2):38-43. doi:10.1016/j.mce.2011.12.019

Yuan X, Cai C, Chen S, Yu Z, Balk SP (2013) Androgen receptor functions in castration-resistant prostate cancer and mechanisms of resistance to new agents targeting the androgen axis. Oncogene doi:10.1038/onc.2013.235

doi:10.1186/2193-1801-3-574

Cite this article as: Bremmer et al:: Increased expression of CYP17A1

indicates an effective targeting of the androgen receptor axis in

castration resistant prostate cancer (CRPC). SpringerPlus 2014 3:574.

\section{Submit your manuscript to a SpringerOpen ${ }^{\circ}$ journal and benefit from:}

- Convenient online submission

- Rigorous peer review

- Immediate publication on acceptance

- Open access: articles freely available online

- High visibility within the field

- Retaining the copyright to your article

Submit your next manuscript at $\gg$ springeropen.com 